\title{
Moderately elevated preconception fasting plasma total homocysteine is a risk factor for psychological problems in childhood
}

\author{
Joana Roigé-Castellví ${ }^{1,2}$, Michelle Murphy ${ }^{3,4}$, Joan Fernández-Ballart ${ }^{3,4}$ and \\ Josefa Canals $1,2, *$ \\ 'Department of Psychology, Universitat Rovira I Virgili, Carretera de Valls s/n, 43007 Tarragona, Spain: ${ }^{2}$ Research \\ Center for Behavioral Assessment (CRAMC), Universitat Rovira i Virgili, Tarragona, Spain: ${ }^{3}$ Department of Basic \\ Medical Sciences, Universitat Rovira i Virgili and IISPV, Reus, Spain: ${ }^{4}$ Biomedical Research Networking Center for \\ the Pathophysiology of Obesity, Carlos III Institute of Health, Madrid, Spain
}

Submitted 12 February 2018: Final revision received 16 August 2018: Accepted 12 November 2018: First published online 14 January 2019

\begin{abstract}
Objective: We investigated the effect of maternal preconception fasting plasma total homocysteine (tHcy) on psychological problems in children aged 6 years from normal pregnancies.

Design: A longitudinal study was carried out from preconception, throughout each trimester of pregnancy, until 6 years of age in the offspring. Fasting blood samples at 2-10 weeks preconception and non-fasting samples at birth were collected. Parents completed the Child Behaviour Checklist (CBCL) and teachers the Inattention-Overactivity with Aggression (IOWA) scale for the 6-year-old children. Setting: Elevated tHcy during pregnancy has been associated with several adverse outcomes and with neurodevelopmental impairment in the offspring.

Participants: The initial sample consisted of 139 healthy non-pregnant women who were planning on becoming pregnant. Eighty-one mother-child dyads were followed from preconception until 6 years of age.

Results: After adjusting for covariables, multiple linear regression models showed that higher preconception tHcy was associated with higher scores in internalizing dimension $(\beta=0.289 ; P=0.028)$, specifically in withdrawn behaviour $(\beta=0.349$; $P=0.009)$, anxiety/depression $(\beta=0.303 ; \quad P=0.019)$ and social problems $(\beta=0.372 ; P=0.009)$. Aggressive behaviour in the school setting was higher in children whose mothers had higher preconception tHcy $(\beta=0 \cdot 351 ; P=0 \cdot 014)$. Conclusions: Moderately elevated preconception tHcy may increase the risk of psychological problems in offspring during childhood. These findings add to the evidence that maternal nutritional status, even before being pregnant, can affect later offspring health and may be important to consider when developing future public health policy.
\end{abstract}

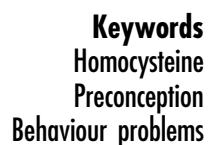

Homocysteine Behaviour problems
The one-carbon metabolic network plays a crucial role in cellular metabolism and proliferation and affects reproductive and pregnancy outcomes, as well as the future health of the offspring ${ }^{(1)}$. The metabolic network is essential for DNA synthesis and repair, as well as for providing methyl groups for epigenetic regulatory processes. Fasting plasma total homocysteine (tHcy) is a useful biomarker of the network. Homocysteine (Hcy) is an intermediate in the network, and folate, vitamins $B_{12}$ and $\mathrm{B}_{6}$, as well as other micronutrients, participate in its metabolism $^{(2)}$. Plasma tHcy acts as a global indicator of status in folate and vitamin $\mathrm{B}_{12}{ }^{(3)}$.
Accumulation of Hcy in nerve cells acts as a potentially toxic substance for the nervous system because it promotes excitotoxicity and damages neuronal DNA, which may lead to neuroanatomical disturbances ${ }^{(4)}$, cognitive impairment and several neurodegenerative disorders in the elderly ${ }^{(5-7)}$. Elevated pregnancy tHcy is a strong and independent risk factor for adverse outcomes in the offspring such as neural tube defects $^{(8)}$, low birth weight $^{(9,10)}$ and congenital heart defects ${ }^{(11)}$. Supplementing mothers with $400 \mu \mathrm{g}$ folic acid daily is widely recommended from periconception throughout the first trimester to prevent adverse effects of folate deficiency on 
fetal development ${ }^{(12,13)}$. Folic acid supplementation is one of the factors that contributes to lowering of tHcy during pregnancy ${ }^{(14,15)}$.

In terms of neurodevelopment, Murphy et al. ${ }^{(16)}$ reported that moderately elevated preconception tHcy (>9.0 $\mu \mathrm{mol} / \mathrm{l})$ was associated with greater probabilities of lower psychomotor ability (Bayley Scale of Infant Development) in 4-month-old infants and worse cognitive performance in 6-year-old children (Wechsler Preschool and Primary Scale of Intelligence). Additionally, Ars et $a l^{(17)}$ reported that elevated maternal tHcy $(>9 \cdot 1 \mu \mathrm{mol} / \mathrm{l})$ in early pregnancy (mean gestational age 13.5 weeks) was associated with worse performance in language and visuo-spatial cognitive domains in children between 6 and 8 years of age. Likewise, pregnancy status of other micronutrients involved in one-carbon metabolism (B vitamins principally) has been associated with improved child cognitive performance as well as behavioural outcomes in school-aged children ${ }^{(18)}$.

Regarding behavioural problems, maternal tHcy is also related to long-term emotional disturbances and peer problems in children ${ }^{(19)}$. It has been suggested that periconception folic acid supplement use may protect against behavioural problems ${ }^{(20)}$ and neurodevelopmental disorders such as autism spectrum disorders (ASD) in offspring ${ }^{(21-23)}$. Despite this evidence, some studies did not corroborate the adverse effects of high tHcy from 4 weeks prior and through to 8 weeks after the last menstrual period (by three 4-week periods) or low folate status on behavioural problems in the offspring ${ }^{(24)}$. In fact, recent studies even reported that high maternal intake of folic acid $(\geq 1000 \mu \mathrm{g} / \mathrm{d})$ during pregnancy (10-13 and 28-32 gestational weeks) could have a damaging effect on neurodevelopment in the offspring at $4-5$ years of age ${ }^{(25,26)}$. Furthermore, in an ongoing prospective birth cohort study on early-life determinants of autism (the Boston Birth Cohort co-led by the Center on the Early Life Origins of Diseases), pregnancy tHcy did not predict the offspring's ASD risk, but this risk was highest in children whose mothers had very high blood folate level $(>59 \mathrm{nmol} / \mathrm{l})$ and vitamin $\mathrm{B}_{12}(>600 \mathrm{pmol} / \mathrm{l})$ right after giving birth. Mandatory fortification of flour in the USA with folic acid has been in place since 1998 and numerous countries have since implemented the same policy. The debate regarding the benefit of prenatal folic acid supplementation to child health is growing in this context. Other authors ${ }^{(27)}$ report that excessive intake from supplementation combined with fortification may have detrimental effects on child health. In European countries, there is no mandatory fortification and although voluntary fortification is present in many countries, folate status of the general population is generally relatively low compared with those where mandatory fortification is in place ${ }^{(28)}$. Additionally, variation in the genes regulating nutrient status may indirectly affect maternal-to-infant nutrient transfer ${ }^{(27)}$.

To the best of our knowledge, no previous study has investigated whether preconception tHcy affects psychological problems in the children. We hypothesized that moderately elevated preconception tHcy is associated with behavioural and emotional problems in the offspring in mid-childhood. The aim of the present study was to investigate the effect of maternal tHcy measured 2-10 weeks before conception on psychological problems in children aged 6 years from uncomplicated pregnancies.

\section{Materials and methods}

\section{Study population}

The longitudinal preconception study was carried out from before conception (2-10 weeks before pregnancy), throughout each trimester of pregnancy, until 6 years of age in the offspring. The study design ${ }^{(14)}$ and data from the children at 6 years have been reported previously ${ }^{(29)}$.

Participants in the preconception phase of the study were healthy non-pregnant women aged $18-35$ years who were planning on becoming pregnant. Recruitment was carried out by the Unit of Preventive Medicine and Public Health, Faculty of Medicine and Health Sciences, Universitat Rovira i Virgili in collaboration with the Unit of Obstetrics and Gynaecology, Sant Joan University Hospital Reus. The psychological assessment was performed by the Department of Psychology.

The study was approved by St. Joan Hospital's (Reus) Ethics Committee and signed informed consent was obtained from all participating volunteers.

Briefly, during the preconception phase 139 women volunteered to participate in the study. After application of the exclusion criteria such as the presence of chronic illness affecting nutritional status, infertility, failure to conceive or miscarriage after entering the study, ninety-two women went on to complete successful pregnancies with complete mother-newborn dyad information available. Of these, eighty-one agreed to participate in the follow-up phase in the mothers and children aged 6 years. The study design is shown in Fig. 1.

At the time of the study, recommendation of periconception folic acid supplement use was not protocol in Spain. Coinciding with Fe supplementation in mid-late pregnancy, some women took multivitamin supplements.

\section{Blood sample collection and analyses of total bomocysteine}

Fasting blood samples from the antecubital vein were collected into EDTA-K 3 vacutainers between days 7 and 14 of the menstrual cycle. If participants did not become pregnant within three menstrual periods after the first preconception blood sample, another sample was taken until becoming pregnant. Similarly, blood samples were taken at 7.5-8 gestational weeks (between 53 and $59 \mathrm{~d}$ after the first day of their last menstrual period), 20 and 32 gestational weeks and on admission to hospital with confirmed labour.

Blood samples were kept refrigerated and plasma was separated by centrifugation strictly within less than $2 \mathrm{~h}$ 


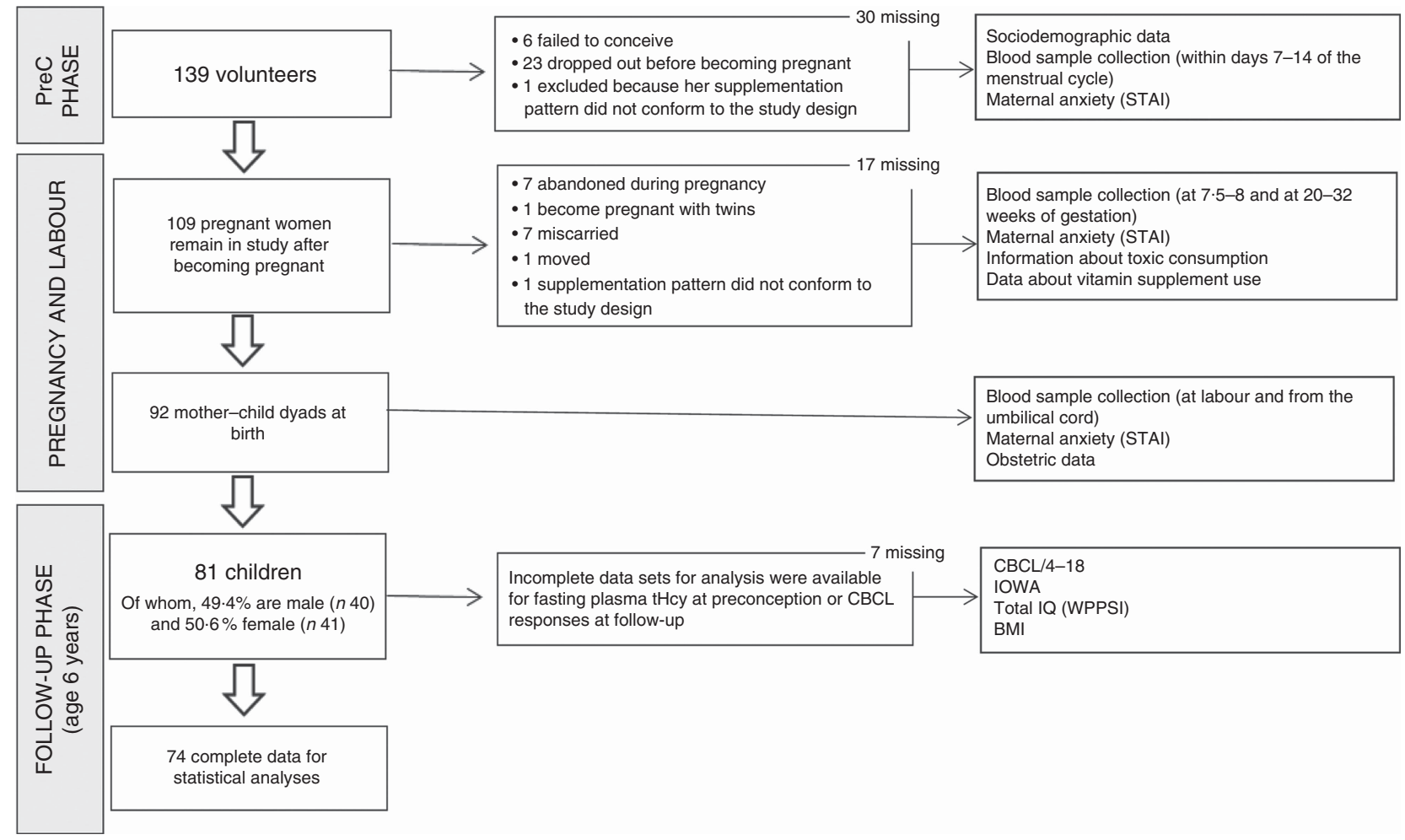

Fig. 1 Flowchart showing the number of participants throughout the study (PreC, preconception; STAl; State-Trait Anxiety Inventory; tHcy, total homocysteine; CBCL/4-18, Child Behaviour Checklist; IOWA, Inattention-Overactivity with Aggression; IQ, intelligence quotient; WPPSI, Wechsler Preschool and Primary Scale of Intelligence)

of collection. Plasma from the pregnancy phase was stored at $-20^{\circ} \mathrm{C}$ and from the follow-up phase at $-70^{\circ} \mathrm{C}$ before tHcy determination using the IMx homocysteine immunoassay (Abbott Laboratories Diagnostics Division, Abbott Park, IL, USA). A more detailed description of sample collection and analysis has been reported previously ${ }^{(14)}$.

\section{Assessment of psychological problems}

The Child Behaviour Checklist (CBCL/4-18) $)^{(30)}$ is an extensively used report form to identify emotional and behaviour problems in children. It is a questionnaire consisting of 118 items, completed by parents, regarding their children's psychological problems. This instrument has nine syndrome scales (withdrawn, anxious/depressed, somatic complaints, social problems, thought problems, attention problems, delinquent behaviour, aggressive behaviour and sex problems); two dimension scales (internalizing dimension, consisting of withdrawn, somatic complaints and anxious/depressed syndromes; and externalizing dimension, consisting of delinquent behaviour and aggressive behaviour); and the total psychological problems scale. In the present study, we applied a Catalan version of this test (Cronbach's $\alpha$ coefficient ranged from 0.60 to 0.87 ), using the T-score for multicultural data.

To evaluate child behaviour based on teacher responses, we used the Inattention-Overactivity with Aggression
(IOWA) Conners' Teachers' rating scale ${ }^{(31)}$. IOWA is a behavioural rating scale with ten items (which range from 'not all' until 'very much') divided into two scales: aggressive behaviour and hyperactivity. We used a Catalan version adapted for the present study, which had an adequate internal consistency (Cronbach's $\alpha$ ranged from 0.84 to $0 \cdot 80$ ).

\section{Covariates}

Maternal anxiety was assessed at preconception, at each trimester of pregnancy, and at $3 \mathrm{~d}$ and 1 month postpartum using the State-Trait Anxiety Inventory (STAI) ${ }^{(32)}$. For the analyses of the current study, we used the trait anxiety mean score from all assessments.

Smoking habits were recorded in periodic interviews carried out from preconception throughout pregnancy.

Data regarding medication and/or vitamin supplement use as well as sociodemographic parameters including parental education were also recorded in these interviews. None of the women took supplements before mid-pregnancy.

The total intelligence quotient (IQ) of the children at 6 years was assessed by the Wechsler Preschool and Primary Scale of Intelligence (WPPSI) ${ }^{(33)}$. WPPSI is an individually administered IQ test and consists of ten sub-tests which form the verbal and manipulative index, the sum of which gives the total IQ.

We also included birth weight and child BMI at 6 years in the models exploring the relationship between 
preconception tHcy and psychological outcomes in the children.

\section{Statistical analyses}

To explore the relationship between preconception tHcy and psychological problems of offspring in childhood, we stratified preconception tHcy into tertiles. The highest tertile was designated as the moderately elevated group while the middle and lowest tertiles were designated as normal. Student's unpaired $t$ tests and $\chi^{2}$ analyses were used to compare the sociodemographic and child characteristics for each subscale of the CBCL/4-18 and IOWA tests between the tHcy groups.

To investigate the effect of maternal preconception tHcy on psychological problems, unadjusted linear regressions were performed for each subscale. Then, we performed the same multiple linear regressions including covariates (by the enter method) in separate models. The covariates included were birth weight, parental education (combined both maternal and parental), smoking during pregnancy, maternal trait anxiety during pregnancy (the mean score at different times of pregnancy), maternal tHcy at labour, and BMI and total IQ of children at age 6 years. Child sex and maternal multivitamin supplement use during the second and third trimesters were also tested in the models, but they were not significantly associated with any of the dependent variables and so were not included in the models in order to maintain an acceptable proportion of covariates per case.

All statistical analyses were performed with the statistical software package IBM SPSS Statistics version 23.

\section{Results}

Descriptive preconception and childhood data are reported in Table 1. At preconception, mean maternal age was 29.6 years and mean tHcy was $8.53 \mu \mathrm{mol} / 1$. Thirty per cent of the women were smokers during pregnancy. Regarding the children, forty were boys and forty-one were girls and mean birth weight was $3247.90 \mathrm{~g}$ (ranging from $1950 \mathrm{~g}$ to $4690 \mathrm{~g}$ ). At age 6 years, mean BMI was $17 \cdot 30 \mathrm{~kg} / \mathrm{m}^{2}$ (ranging from 13.55 to $24.94 \mathrm{~kg} / \mathrm{m}^{2}$ ). The mean total IQ (WPPSI) was normal-high (116.33; ranging from 83 to 144). Moderately elevated and normal preconception tHcy groups were created based on tHcy in the highest tertile ( $\geq 9.04 \mu \mathrm{mol} / \mathrm{l} ; n$ 24) or below this ( $n$ 52), respectively. Differences in maternal and child characteristics between tHcy groups are shown in Table 1. We found a significantly higher frequency of both multiparous women and males in the normal tHcy group compared with the moderately elevated tHcy group.

CBCL/4-18 and IOWA scores according to maternal preconception tHcy category are reported in Table 2. The mean scores for CBCL/4-18 total, internalizing and externalizing problems were within the normal range $(54.33$, 54.21 and 54.45, respectively). Several mean scores were higher in children born to mothers with moderately elevated preconception tHcy compared with those born to mothers with normal preconception tHcy, although these differences were not significantly different between the groups.

Table 3 shows the significant multiple linear regression models of the effect of preconception tHcy on behaviour and emotional problems of children at 6 years of age. In unadjusted models, children of mothers with moderately elevated preconception tHcy had significantly higher scores on CBCL/4-18 subscales for withdrawn (corrected $R^{2}=11 \cdot 6 ; P=0.002$ ), social problems (corrected $R^{2}=6 \cdot 6$; $P=0.016$ ) and aggressive behaviour (corrected $R^{2}=4 \cdot 7$; $P=0.037)$.

In adjusted models, more subscales were observed to be significantly associated with preconception tHcy. These models showed that preconception tHcy was positively associated with withdrawn behaviour $(\beta=0.349$, $P=0.009), \quad$ anxiety/depression $\quad(\beta=0.303, \quad P=0.019)$, social problems $(\beta=0.372, P=0.009)$ and internalizing dimension $(\beta=0.289, P=0.028)$ in $\mathrm{CBCL} / 4-18$, always jointly with maternal anxiety. In IOWA subscales, we found that aggressive behaviour was significantly higher in children from mothers who had moderately elevated preconception tHcy $(\beta=0 \cdot 351, P=0 \cdot 014$; see Table 3$)$.

\section{Discussion}

The aim of the present study was to investigate the association between maternal preconception tHcy and psychological problems in offspring in a long-term prospective study. To test our hypothesis, we first performed comparisons between groups based on tertile of maternal preconception tHcy. So, the moderately elevated tHcy category was composed of the highest tertile $(\geq 9.04 \mu \mathrm{mol} / \mathrm{l})$ and compared with the normal group (middle and lowest tertiles). This cut-off for the highest tertile tHcy is similar to that reported for women aged 18-35 years, non-users of vitamin B supplements $(\geq 9.55 \mu \mathrm{mol} / \mathrm{l})$, from the same geographical area ${ }^{(34)}$. Murphy et al. previously reported in this same cohort of mothers and children that plasma folate tended to be lower in mothers with moderately elevated tHcy compared with those with normal tHcy at various time points as well as in the child. No differences in plasma cobalamin were observed between the two groups ${ }^{(16)}$. On the other hand, mandatory folic acid fortification is absent in Spain and the plasma folate concentrations reported in Murphy et al.'s study ${ }^{(16)}$ show that the cohort was relatively free of exposure to high folic acid intake due to supplement use and/or mandatory folic acid fortification.

Regarding comparison between tHcy groups, the analyses did not show any significant results, only a tendency for higher score in withdrawn behaviour was observed in 
Table 1 Mother and child characteristics from the preconception to follow-up stage and differences between maternal preconception total homocysteine groups (PreConception Study, pregnancy phase 1992-1996; child follow-up stage 1998-2002. Reus, Spain)

\begin{tabular}{|c|c|c|c|c|c|c|c|c|}
\hline & \multicolumn{2}{|c|}{ Total sample } & \multicolumn{2}{|c|}{$\begin{array}{l}\text { Normal tHcy } \\
(<9.04 \mu \mathrm{mol} / \mathrm{l})\end{array}$} & \multicolumn{2}{|c|}{$\begin{array}{c}\text { Moderately elevated tHcy } \\
(\geq 9.04 \mu \mathrm{mol} / \mathrm{l})\end{array}$} & \multirow[b]{2}{*}{$t / x^{2}$} & \multirow[b]{2}{*}{$P$} \\
\hline & Mean & $95 \% \mathrm{Cl}$ & $\begin{array}{l}\text { Mean } \\
\text { or } \%\end{array}$ & $\begin{array}{l}\mathrm{SD} \\
\text { or } n\end{array}$ & $\begin{array}{l}\text { Mean } \\
\text { or } \%\end{array}$ & $\begin{array}{l}\mathrm{SD} \\
\text { or } n\end{array}$ & & \\
\hline \multicolumn{9}{|l|}{ PreC/pregnancy } \\
\hline Maternal age at PreC (years) & $29 \cdot 60$ & $29 \cdot 0,30 \cdot 2$ & 29.87 & $2 \cdot 86$ & 28.92 & 2.55 & $1.388 \S$ & 0.169 \\
\hline thcy at labour $(\mu \mathrm{mol} / \mathrm{l})$ & $2 \cdot 89$ & $7.54,8.91$ & 7.57 & 2.52 & 9.66 & 3.21 & $-2 \cdot 913 \S$ & 0.005 \\
\hline PreC tHcy $(\mu \mathrm{mol} / \mathrm{l})$ & 8.53 & $7 \cdot 54,8.45$ & $7 \cdot 28$ & $1 \cdot 26$ & $11 \cdot 30$ & $2 \cdot 76$ & $-8.628 \S$ & 0.000 \\
\hline Anxiety during pregnancyt (score) & $16 \cdot 03$ & $14 \cdot 68,17 \cdot 32$ & $15 \cdot 95$ & $6 \cdot 69$ & $16 \cdot 97$ & $5 \cdot 23$ & $-0.651 \S$ & 0.517 \\
\hline Smoke (\%) & & & & & & & & \\
\hline $\begin{array}{l}\text { During pregnancy or postnatally } \\
\text { Parity (\%) }\end{array}$ & $30 \cdot 00$ & $20 \cdot 73,40 \cdot 69$ & 28.80 & 15 & $29 \cdot 25$ & 7 & $0.000 \|$ & 0.983 \\
\hline Multiparous & 38.30 & $28 \cdot 18,49 \cdot 18$ & $48 \cdot 11$ & 25 & $20 \cdot 88$ & 5 & $5 \cdot 101 \|$ & 0.024 \\
\hline Parental education (\%) & & & & & & & & \\
\hline Low & 37.00 & $27.06,47.93$ & 36.50 & 19 & 41.74 & 10 & $0.238 \|$ & 0.888 \\
\hline Mid & 23.50 & $15.19,33.59$ & $25 \cdot 00$ & 13 & $20 \cdot 88$ & 5 & & \\
\hline High & 39.50 & $29 \cdot 32,50 \cdot 43$ & 38.57 & 20 & 37.57 & 9 & & \\
\hline \multicolumn{9}{|l|}{ At birth } \\
\hline Gestational age (weeks) & 39.95 & $38.78,39.22$ & 40.06 & 1.45 & $39 \cdot 77$ & 2.08 & $0.685 \S$ & 0.496 \\
\hline Birth weight $(\mathrm{g})$ & $3247 \cdot 90$ & $3144 \cdot 22,3349 \cdot 78$ & $3327 \cdot 69$ & $469 \cdot 54$ & $3124 \cdot 17$ & $443 \cdot 14$ & $1 \cdot 787 \S$ & 0.078 \\
\hline Child sex (\%) & & & & & & & & \\
\hline $\begin{array}{l}\text { Male } \\
\text { At follow-up (age } 6 \text { years) }\end{array}$ & $49 \cdot 40$ & $39 \cdot 80,61.39$ & $57 \cdot 70$ & 30 & 33.32 & 8 & $3 \cdot 890 \|$ & 0.048 \\
\hline \multicolumn{9}{|l|}{ At follow-up (age 6 years) } \\
\hline BMI $\left(\mathrm{kg} / \mathrm{m}^{2}\right)$ & $17 \cdot 30$ & $16 \cdot 56,17 \cdot 43$ & $17 \cdot 22$ & $2 \cdot 30$ & $17 \cdot 48$ & $2 \cdot 17$ & $-0.471 \S$ & 0.639 \\
\hline Total IQł (score) & $116 \cdot 33$ & $113 \cdot 15,118 \cdot 85$ & 117.59 & 13.33 & 113.75 & $12 \cdot 84$ & $0.958 \S$ & 0.243 \\
\hline Manipulative index & $117 \cdot 71$ & $114.37,119.63$ & 118.92 & 11.45 & $115 \cdot 17$ & 14.74 & $1.205 \S$ & 0.232 \\
\hline Verbal index & $110 \cdot 51$ & $107 \cdot 37,112.63$ & 111.41 & 13.52 & $108 \cdot 79$ & $12 \cdot 21$ & $0.806 \S$ & 0.423 \\
\hline
\end{tabular}

PreC, preconception; tHcy, total homocysteine; IQ, intelligence quotient.

${ }^{*}$ Fasting plasma tHcy is geometric mean.

†Mean of State-Trait Anxiety Inventory scores from PreC to immediate postpartum.

$\ddagger$ Wechsler Preschool and Primary Scale of Intelligence.

$\S t$ Test: mean, SD and $t$ value.

$\| x^{2}$ Test: $\%, n$ and $x^{2}$ value.

Table 2 Comparison of child psychological problems at age 6 years between maternal preconception total homocysteine groups (PreConception Study, pregnancy phase 1992-1996; child follow-up stage 1998-2002. Reus, Spain)

\begin{tabular}{|c|c|c|c|c|c|c|}
\hline \multirow[b]{2}{*}{ Child psychological problems } & \multicolumn{2}{|c|}{$\begin{array}{l}\text { Normal tHcy } \\
(<9.04 \mu \mathrm{mol} / \mathrm{l})\end{array}$} & \multicolumn{2}{|c|}{$\begin{array}{c}\text { Moderately elevated tHcy } \\
(\geq 9.04 \mu \mathrm{mol} / \mathrm{l})\end{array}$} & \multirow[b]{2}{*}{$t^{*}$} & \multirow[b]{2}{*}{$P$} \\
\hline & Mean & SD & Mean & SD & & \\
\hline \multicolumn{7}{|l|}{ CBCL/4-18 } \\
\hline Withdrawn & $55 \cdot 35$ & $5 \cdot 24$ & 57.88 & $6 \cdot 23$ & -1.828 & 0.072 \\
\hline Somatic complaints & $57 \cdot 16$ & 6.59 & 57.83 & 7.66 & -0.393 & 0.695 \\
\hline Anxious/depressed & $54 \cdot 33$ & $6 \cdot 22$ & $55 \cdot 38$ & $6 \cdot 12$ & -0.679 & 0.499 \\
\hline Social problems & 53.61 & 6.50 & 53.96 & 5.52 & -0.228 & 0.820 \\
\hline Thought problems & 53.27 & $6 \cdot 34$ & $54 \cdot 13$ & 7.80 & -0.502 & 0.617 \\
\hline Attention problems & 55.88 & 7.51 & $56 \cdot 50$ & 8.94 & -0.312 & 0.756 \\
\hline Delinquent behaviour & $55 \cdot 12$ & $6 \cdot 87$ & 56.63 & $6 \cdot 76$ & -0.891 & 0.376 \\
\hline Aggressive behaviour & 54.86 & 6.46 & 57.21 & 7.90 & -1.363 & 0.177 \\
\hline Sex problems & $54 \cdot 73$ & $7 \cdot 10$ & $55 \cdot 96$ & $8 \cdot 76$ & -0.650 & 0.518 \\
\hline Internalizing dimension & 53.71 & 8.73 & 55.42 & 9.73 & -0.763 & 0.448 \\
\hline Externalizing dimension & $52 \cdot 80$ & 8.62 & 55.79 & 9.03 & -1.379 & 0.172 \\
\hline Total problems & 53.25 & 7.45 & $55 \cdot 60$ & 8.80 & $-1 \cdot 201$ & 0.234 \\
\hline \multicolumn{7}{|l|}{ IOWA } \\
\hline Hyperactivity & $3 \cdot 21$ & $2 \cdot 79$ & $2 \cdot 88$ & 3.02 & 0.475 & 0.636 \\
\hline Aggressive behaviour & 1.42 & 1.84 & 1.67 & 2.09 & -0.513 & 0.610 \\
\hline
\end{tabular}

tHcy, total homocysteine; CBCL/4-18, Child Behaviour Checklist; IOWA, Inattention-Overactivity with Aggression Homogeneity of variances were assumed for all the subscales.

$\mathrm{CBCL} / 4-18$ subscales, $\mathrm{df}=73$; IOWA subscales, $\mathrm{df}=74$

${ }^{\star} t$ Test: $t$ value. 
Table 3 Significant multiple linear regression models of the effect of maternal preconception total homocysteine level on child psychological problems at age 6 years (PreConception Study, pregnancy phase 1992-1996; child follow-up stage 1998-2002. Reus, Spain)

\begin{tabular}{|c|c|c|c|c|c|c|c|c|c|}
\hline & \multicolumn{4}{|c|}{ Unadjusted model } & \multicolumn{5}{|c|}{ Adjusted model } \\
\hline & $\beta$ & $P$ & $F_{(1,72)}$ & $\mathrm{c} R^{2}$ & $\beta$ & $P$ & $P$ & $F_{(8,63)}$ & $\mathrm{c} R^{2}$ \\
\hline \multicolumn{10}{|l|}{ CBCL/4-18 } \\
\hline Withdrawn & \multirow{3}{*}{0.358} & \multirow[t]{3}{*}{0.002} & \multirow[t]{3}{*}{$10 \cdot 46$} & \multirow[t]{3}{*}{$11 \cdot 60$} & & & \multirow[t]{3}{*}{0.001} & \multirow[t]{3}{*}{3.88} & \multirow[t]{3}{*}{$26 \cdot 80$} \\
\hline Maternal PreC tHcy & & & & & $\begin{array}{r}0.349 \\
-0.394\end{array}$ & 0.009 & & & \\
\hline $\begin{array}{l}\text { Birth weight } \\
\text { Maternal anxiety }\end{array}$ & & & & & $\begin{array}{r}-0.394 \\
0.247\end{array}$ & $\begin{array}{l}0.001 \\
0.031\end{array}$ & & & \\
\hline Anxious/depressed & \multirow{4}{*}{0.216} & \multirow[t]{4}{*}{0.066} & \multirow[t]{4}{*}{3.48} & \multirow[t]{4}{*}{3.30} & & & \multirow[t]{4}{*}{0.000} & \multirow[t]{4}{*}{4.50} & \multirow[t]{4}{*}{$30 \cdot 80$} \\
\hline Maternal PreC tHcy & & & & & 0.303 & 0.019 & & & \\
\hline Maternal anxiety & & & & & 0.492 & 0.000 & & & \\
\hline $\mathrm{BMI}$ & & & & & -0.256 & 0.023 & & & \\
\hline Social problems & \multirow{3}{*}{0.281} & \multirow[t]{3}{*}{0.016} & \multirow[t]{3}{*}{6.07} & \multirow[t]{3}{*}{6.60} & & & \multirow[t]{3}{*}{0.020} & \multirow[t]{3}{*}{$2 \cdot 53$} & \multirow[t]{3}{*}{$16 \cdot 30$} \\
\hline Maternal PreC tHcy & & & & & 0.372 & 0.009 & & & \\
\hline Maternal anxiety & & & & & 0.280 & 0.022 & & & \\
\hline Aggressive behaviour & \multirow{3}{*}{0.245} & 0.037 & 4.51 & 4.70 & & & & & \\
\hline Maternal PreC tHcy & & & & & & & & & \\
\hline Internalizing dimension & & 0.052 & 3.90 & 3.90 & & & \multirow[t]{5}{*}{0.001} & \multirow[t]{5}{*}{4.07} & \multirow[t]{5}{*}{28.00} \\
\hline Maternal PreC tHcy & \multirow[t]{4}{*}{0.228} & & & & 0.289 & 0.028 & & & \\
\hline Birth weight & & & & & -0.238 & 0.037 & & & \\
\hline BMI & & & & & -0.345 & 0.003 & & & \\
\hline Maternal anxiety & & & & & 0.421 & 0.000 & & & \\
\hline IOWA & & & & & & & & & \\
\hline Aggressive behaviour & \multirow{4}{*}{0.202} & \multirow{4}{*}{0.084} & \multirow{4}{*}{3.06} & 2.80 & & & 0.021 & 2.52 & $16 \cdot 20$ \\
\hline Maternal PreC tHcy & & & & & 0.351 & 0.014 & & & \\
\hline Birth weight & & & & & 0.268 & 0.029 & & & \\
\hline Parental education & & & & & -0.247 & 0.047 & & & \\
\hline
\end{tabular}

$\mathrm{c} R^{2}$, corrected $R^{2}$; PreC, preconception; tHcy, total homocysteine; CBCL/4-18, Child Behaviour Checklist; IOWA, Inattention-Overactivity with Aggression; STAI, State-Trait Anxiety Inventory; IQ, intelligence quotient;

Adjusted models include the following covariates (enter method): birth weight (g), BMI (kg/ $\mathrm{m}^{2}$ ) at age 6 years, parental education (combined both maternal and paternal), smoking during pregnancy, mean of anxiety during pregnancy (STAI), total IQ at age 6 years (WPPSI) and maternal tHcy at birth. 
the highest tertile. However, both adjusted and non-adjusted models showed that children born to mothers with higher tHcy concentrations at preconception scored higher for withdrawn and social problems. In the adjusted models, CBCL/4-18 anxiety/depression scale and IOWA aggressive behaviour were additionally predicted by preconception tHcy. From the point of view of neurological maturity, social behaviour is related with many brain regions and neural circuits which begin their development in the period of early corticogenesis. In mice, Belinson et al. ${ }^{(35)}$ demonstrated a fetal origin for social and repetitive behaviour deficits seen in disorders such as ASD. Considering that the manifestations of withdrawn and social problems are, among others, typical clinical symptoms of ASD, the observed association between these manifestations and tHcy could support the preventive role of prenatal folic acid in the onset of ASD found by other authors ${ }^{(36,37)}$. However, in our study no diagnostic assessment of ASD was performed, and the withdrawn and social problems could also be symptoms of other disorders such as emotional disorders. In contrast, recent studies have not been able to substantiate a beneficial effect on child risk of ASD by maternal folic acid supplementation in the periconceptional period ${ }^{(38)}$. High maternal plasma folate at birth was not associated with reduced ASD risk either ${ }^{(39,40)}$. Recently, Raghavan et al. ${ }^{(37)}$ reported a U-shaped relationship between folate and $\mathrm{B}_{12}$ levels and ASD risk. On the other hand, regardless of the level of maternal Hcy and folate, some authors suggest that children with ASD may have defects in folic acid absorption that play a role in the onset of $\operatorname{ASD}^{(40)}$. Regarding the relationship found between anxiety/depression problems (and internalizing dimension) and higher preconception tHcy, our data are comparable to the results of other authors ${ }^{(36,41)}$. Steenweg-De-Graaff et al. ${ }^{(41)}$ found a higher risk of emotional problems in children of mothers who started using folic acid supplements late or did not use supplements at all than in children whose mothers started periconceptionally. In our study, also the women started supplementation after mid-pregnancy, which supports the idea that the protective role of folic acid on neurodevelopment of the child is in very early pregnancy. Steenweg-De-Graaff et al $^{(41)} \mathrm{did}$ not find a relationship between prenatal folate deficiency and behaviour problems in the offspring, in contrast to findings of the present study showing an association between preconception tHcy and aggressive behaviours. Although aggressiveness is an externalizing manifestation, in the clinical setting it is not infrequent to find that children express their emotional distress with irritability and aggressive behaviour.

It is relevant to remark that preconception tHcy was associated with higher psychological problem scores regardless of maternal tHcy at birth, supporting the importance in neurodevelopment of optimal tHcy in early pregnancy. In this sense, other researchers did not find significant associations between mid-late pregnancy tHcy concentrations and childhood cognitive functions ${ }^{(42)}$ or neurodevelopment ${ }^{(43)}$.
Our study confirms the relevance of considering preconception tHcy. The strength of the study is the precise timing of preconception tHcy measurements from mothers, which were performed within 2-10 weeks of becoming pregnant and in a specific window of the preconception menstrual cycle (specifically during the periovulation phase between days 7 and 12). In this way, it was ensured that the preconception blood sample reflected the habitual maternal tHcy levels, because tHcy normally decreases rapidly during the first half of the pregnancy period ${ }^{(14)}$. Therefore, the preconception thcy sample is free of the physiological effects of pregnancy that affect tHcy concentrations. The strong and innovative aspect of the study lies in its design from preconception throughout childhood and that we were extremely careful to optimize the precision of tHcy determinations as near as possible to neurogenesis in the embryo. Furthermore, extensive and accurate lifestyle and clinical data were also collected before pregnancy. We were also able to adjust our analysis for late pregnancy tHcy and the sample was homogeneous with respect to the absence of variables which could be risk factors of psychological problems. Several important confounders have been taken into account in the regression models, and prenatal anxiety was a significant predictor of child psychopathological characteristics as previously reported ${ }^{(44)}$.

The small sample size was due to the difficulty in recruiting women at preconception and the commitment to planning determinations from preconception throughout pregnancy and subsequently in the follow-up phase in the child at 6 years after birth. Given that the study followed prospectively a cohort of pregnant women without specific risk factors, we were not inclined to consider the assessment of possible psychopathological diagnoses in this group and this was a potential limitation.

\section{Conclusion}

We conclude that moderately elevated preconception tHcy is associated with increased risk of psychological problems in the offspring, especially of internalizing problems and social problems, although also of aggressive behaviour. Further research is needed to corroborate the role of prenatal tHcy in neuropsychiatric disorders.

\section{Acknowledgements}

Acknowledgements: The biochemical determinations were carried out in Professor Anne Molloy's lab in Trinity College Dublin. Financial support: This study was supported financially by the Comisión Interministerial de Ciencia y Tecnología (grant number CICYT: ALI 89-0388), Fondo de Investigación Sanitaria (grant number FIS:00/0954) and Instituto de Salud Carlos III, Red de Centros en Metabolismo y Nutrición, Madrid, Spain (grant number C03/08). 
The funders had no role in the design, analysis or writing of this article. Conflict of interest: The authors report no conflicts of interest. Authorship: M.M., J.F.-B. and J.C. participated in hypothesis development and designing the study. J.R.-C. was primarily responsible for data analysis and the writing of the paper. All authors revised and approved the final version of the paper. Ethics of buman subject participation: This study was conducted according to the guidelines laid down in the Declaration of Helsinki and all procedures involving human subjects were approved by the St. Joan Hospital's (Reus) Ethics Committee. Written informed consent was obtained from all participating volunteers.

\section{References}

1. Kalhan SC (2016) One carbon metabolism in pregnancy: impact on maternal, fetal and neonatal health. Mol Cell Endocrinol 435, 48-60.

2. Selhub J (2008) Public health significance of elevated homocysteine. Food Nutr Bull 29, 116-125.

3. Brustolin S, Giugliani R \& Félix TM (2010) Genetics of homocysteine metabolism and associated disorders. Braz J Med Biol Res 43, 1-7.

4. Douaud G, Refsum H, de Jager C et al. (2013) Preventing Alzheimer's disease-related gray matter atrophy by B-vitamin treatment. Proc Natl Acad Sci U S A 110, 9523-9528.

5. Haan MN, Miller JW, Aiello AE et al. (2007) Homocysteine, $B$ vitamins, and the incidence of dementia and cognitive impairment: results from the Sacramento Area Latino Study on Aging. Am J Clin Nutr 85, 511-517.

6. Mattson MP \& Shea TB (2003) Folate and homocysteine metabolism in neural plasticity and neurodegenerative disorders. Trends Neurosci 26, 137-146.

7. Seshadri S, Beiser A, Selhub J et al. (2002) Plasma homocysteine as a risk factor for dementia and Alzheimer's disease. $N$ Engl J Med 346, 476-483.

8. Tang K-F, Li Y-L \& Wang H-Y (2015) Quantitative assessment of maternal biomarkers related to one-carbon metabolism and neural tube defects. Sci Rep 5, 8510.

9. Bergen NE, Jaddoe VW, Timmermans S et al. (2012) Homocysteine and folate concentrations in early pregnancy and the risk of adverse pregnancy outcomes: the Generation R Study. BJOG 119, 739-751.

10. Murphy MM, Scott JM, Arija V et al. (2004) Maternal homocysteine before conception and throughout pregnancy predicts fetal homocysteine and birth weight. Clin Chem 50, 1406-1412.

11. Verkleij-Hagoort A, Bliek J, Sayed-Tabatabaei F et al. (2007) Hyperhomocysteinemia and MTHFR polymorphisms in association with orofacial clefts and congenital heart defects: a meta-analysis. Am J Med Genet A 143A, 952-960.

12. Berti C, Biesalski HK, Gärtner R et al. (2011) Micronutrients in pregnancy: current knowledge and unresolved questions. Clin Nutr 30, 689-701.

13. Blumfield ML, Hure AJ, Macdonald-wicks L et al. (2013) Micronutrient intakes during pregnancy in developed countries: systematic review and meta-analysis. Nutr Rev 71, 118-132.

14. Murphy MM, Scott JM, McPartlin JM et al. (2002) The pregnancy-related decrease in fasting plasma homocysteine is not explained by folic acid supplementation, hemodilution, or a decrease in albumin in a longitudinal study. $\mathrm{Am} \mathrm{J}$ Clin Nutr 76, 614-619.
15. McNulty B, McNulty H, Marshall B et al. (2013) Impact of continuing folic acid after the first trimester of pregnancy: findings of a randomized trial of folic acid supplementation in the second and third trimesters. Am J Clin Nutr 98, 92-98.

16. Murphy MM, Fernandez-Ballart JD, Molloy AM et al. (2017) Moderately elevated maternal homocysteine at preconception is inversely associated with cognitive performance in children 4 months and 6 years after birth. Matern Child Nutr 13, e12289.

17. Ars CL, Nijs IM, Marroun HE, et al. (2016) Prenatal folate, homocysteine and vitamin $\mathrm{B}_{12}$ levels and child brain volumes, cognitive development and psychological functioning: the Generation R Study. BrJ Nutr. Published online: 22 January 2016. doi: 10.1017/S0007114515002081.

18. Anjos T, Altmäe S, Emmett P et al. (2013) Nutrition and neurodevelopment in children: Focus on NUTRIMENTHE project. Eur J Nutr 52, 1825-1842.

19. Schlotz W, Jones A, Phillips DIW et al. (2010) Lower maternal folate status in early pregnancy is associated with childhood hyperactivity and peer problems in offspring. $J$ Child Psychol Psychiatry 51, 594-602.

20. Roza SJ, van Batenburg-Eddes T, Steegers E a P et al. (2010) Maternal folic acid supplement use in early pregnancy and child behavioural problems: the Generation R Study. $\mathrm{Br} \mathrm{J}$ Nutr 103, 445-452.

21. DeVilbiss EA, Gardner RM, Newschaffer CJ et al. (2015) Maternal folate status as a risk factor for autism spectrum disorders: a review of existing evidence. Br J Nutr $\mathbf{1 1 4}$, 663-672.

22. Schmidt RJ, Tancredi DJ, Ozonoff S et al. (2012) Maternal periconceptional folic acid intake and risk for developmental delay and autism spectrum disorder: a casecontrol study. Am J Clin Nutr 96, 80-89.

23. Surén P, Roth C, Bresnahan M et al. (2013) Association between maternal use of folic acid supplements and risk of autism spectrum disorders in children. JAMA 309, 570-577.

24. Virk J, Liew Z, Olsen J et al. (2015) Preconceptional and prenatal supplementary folic acid and multivitamin intake and autism spectrum disorders. Autism 20, 710-718.

25. Boyles AL, Yetley EA, Thayer KA et al. (2016) Safe use of high intakes of folic acid: research challenges and paths forward. Nutr Rev 74, 469-474.

26. Valera-Gran D, Navarrete-Muñoz EM, Garcia de la Hera M et al. (2017) Effect of maternal high dosages of folic acid supplements on neurocognitive development in children at 4-5 years of age: the prospective birth cohort Infancia y Medio Ambiente (INMA) study. Am J Clin Nutr 106, 878-887.

27. Selhub J \& Rosenberg IH (2016) Excessive folic acid intake and relation to adverse health outcome. Biochimie 126, $71-78$.

28. Bueno O, Molloy AM, Fernandez-Ballart JD et al. (2016) Common polymorphisms that affect folate transport or metabolism modify the effect of the MTHFR $677 \mathrm{C}>\mathrm{T}$ polymorphism on folate status. J Nutr 146, 1-8.

29. Canals J, Esparó G \& Fernandez-Ballart J (2006) Neonatal behaviour characteristics and psychological problems at 6 years. Acta Paediatr $95,1412-1417$.

30. Achenbach TM (1991) Manual for the Child Behavior Checklist (4-18 and 1991 profile). Burlington, VT: University of Vermont.

31. Loney J \& Milich R (1982) Hyperactivity, inattention and aggression in clinical practice. Adv Dev Behav Pediatr 3, 113-232.

32. Spielberger CD, Gorsuch RL \& Lushene RE (1988) Cuestionario de Ansiedad Estado-Rasgo. Manual de Adaptación Española. Madrid: TEA Ediciones.

33. Wechsler D (1996) Escala de Inteligencia de Wechsler para Preescolar y Primaria, WIPPSI. Manual de Adaptación Española. Madrid: TEA Ediciones. 
34. Murphy MM, Vilella E, Ceruelo S et al. (2002) The MTHFR C677T, APOE, and PON55 gene polymorphisms show relevant interactions with cardiovascular risk factors. Clin Chem 48, 372-375.

35. Belinson H, Nakatani J, Babineau BA et al. (2016) Prenatal $\beta$-catenin/Brn2/Tbr2 transcriptional cascade regulates adult social and stereotypic behaviors. Mol Psychiatry 21, 1417-1433.

36. Wang M, Li K, Zhao D et al. (2017) The association between maternal use of folic acid supplements during pregnancy and risk of autism spectrum disorders in children: a metaanalysis. Mol Autism 8, 51.

37. Raghavan R, Riley AW, Volk H et al. (2017) Maternal multivitamin intake, plasma folate and vitamin $\mathrm{B}_{12}$ levels and autism spectrum disorder risk in offspring. Paediatr Perinat Epidemiol 32, 100-111.

38. Strøm M, Granström C, Lyall K et al. (2017) Research letter: Folic acid supplementation and intake of folate in pregnancy in relation to offspring risk of autism spectrum disorder. Psychol Med 48, 1048-1054.

39. DeVilbiss EA, Magnusson C, Gardner RM, et al. (2017) Antenatal nutritional supplementation and autism spectrum disorders in the Stockholm youth cohort: population based cohort study. BMJ 4273, j4273.

40. Zhou J, Liu A, He F et al. (2018) High prevalence of serum folate receptor autoantibodies in children with autism spectrum disorders. Biomarkers 23, 622-624.

41. Steenweg-De-Graaff J, Roza SJ, Steegers EA et al. (2012) Maternal folate status in early pregnancy and child emotional and behavioral problems: the Generation R Study. Am J Clin Nutr 95, 1413-1421.

42. Veena SR, Krishnaveni GV, Srinivasan K et al. (2010) Higher maternal plasma folate but not vitamin B-12 concentrations during pregnancy are associated with better cognitive function scores in 9-10 year old children in South-India. $J$ Nutr 140, 1014-1022.

43. Tamura T, Goldenberg RL, Chapman VR et al. (2005) Folate status of mothers during pregnancy and mental and psychomotor development of their children at five years of age. Pediatrics 116, 703-708.

44. Glover V (2018) Stress in pregnancy can change fetal and child development. In Transforming Infant Wellbeing: Research, Policy and Practice for the First 1001 Critical Days, pp. 98-106 [P Leach, editor]. Abingdon: Routledge. 